\title{
07.3
}

\section{Струйная печать слоев полианилина для перовскитных солнечных элементов}

\author{
() О.Л. Грибкова, В.А. Кабанова, А.Р. Тамеев, А.А. Некрасов \\ Институт фризической химии и электрохимии им. А.Н. Фрумкина РАН, Москва, Россия \\ E-mail: oxgribkova@gmail.com
}

Поступило в Редакцию 13 мая 2019 г.

В окончательной редакции 13 мая 2019 г.

Принято к публикации 16 мая 2019 г.

\begin{abstract}
Разработаны водорастворимые чернила на основе полианилина для формирования дырочно-транспортных слоев перовскитных солнечных элементов методом струйной печати. На основании исследования оптических свойств и морфологии поверхности слоев комплекса полианилина и полисульфокислоты предложены критерии, определяющие оптимальные условия их печати. Напечатанные слои показали себя перспективными дырочными транспортными слоями для перовскитных солнечных элементов.
\end{abstract}

Ключевые слова: перовскиты, солнечные элементы, полианилин, атомная силовая микроскопия.

DOI: 10.21883/PJTF.2019.17.48215.17875

В течение последних лет гибридные органо-неорганические солнечные элементы (СЭ) на основе перовскитов привлекают пристальное внимание в связи с такими достоинствами, как широкий спектр поглощения света, относительно простой способ приготовления слоев и высокий КПД [1], достигающий значения 23\% [2].

Большое внимание уделяется как разработке состава используемого перовскита, так и методам нанесения его слоя. Наряду с этим важную роль играет подбор зарядотранспортных слоев в СЭ, в частности разработка новых материалов для дырочных транспортных слоев (ДТС). Перспективными материалами для использования в качестве ДТС в перовскитных СЭ с инвертированной структурой являются такие проводящие полимеры, как поли-3, 4-этилендиокситиофен (ПЭДОТ) и полианилин (ПАНИ). Так, ДТС на основе водорастворимого комплекса поли-3, 4-этилендиокситиофена с полистиролсульфокислотой (ПЭДОТ-ПССК) успешно применяются в разработках перовскитных СЭ [3]. Одним из перспективных и активно развиваемых методов для приготовления СЭ является метод струйной печати слоев ПЭДОТ-ПССК [4].

В ряде работ [5-8] показана возможность применения ПАНИ в качестве ДТС в перовскитных СЭ, в том числе и использования водорастворимого комплекса ПАНИ с ПССК [6] и сополимера ПАНИ и ПССК [7]. Однако создание СЭ с ДТС на основе ПАНИ, приготовленного методом струйной печати, ранее не осуществлялось. Нанесение слоев ПАНИ методом струйной печати (inkjet printing) в основном было использовано для создания биологических и химических сенсоров и суперконденсаторов [9-12], причем чернила для печати в этих случаях были на основе органических растворителей.

В то же время проведение химического синтеза ПАНИ в присутствии поли-(2-акриламидо-2-метил-1-пропансульфоновой) кислоты (ПАМПСК) позво- ляет получать его стабильную водную дисперсию (сохранение свойств и состава дисперсии неизменными более двух лет) [13]. В работах [14,15] была показана возможность использования этого комплекса в СЭ с фотоактивным слоем на основе известного композита поли-3-гексилтиофена (Р3НТ) и производного фуллерена РС71ВМ. Слои ПАНИ-ПАМПСК были получены как поливом на горизонтальную подложку [14], так и методом струйной печати [15]. Было обнаружено, что снижение содержания ПАМПСК в комплексе (до $1: 1.25$ и менее) приводит к образованию твердой фазы ПАНИ в растворе $[13,15]$, что исключает использование состава 1:1.25 и менее для струйной печати. Кроме того, увеличение концентрации мономера (более $0.01 \mathrm{M}$ ) и ПАМПСК при синтезе приводит к образованию гелеобразных агрегатов комплекса ПАНИ-ПАМПСК, что также не удовлетворяет требованиям, предъявляемым к растворам для печати. На примере СЭ на основе

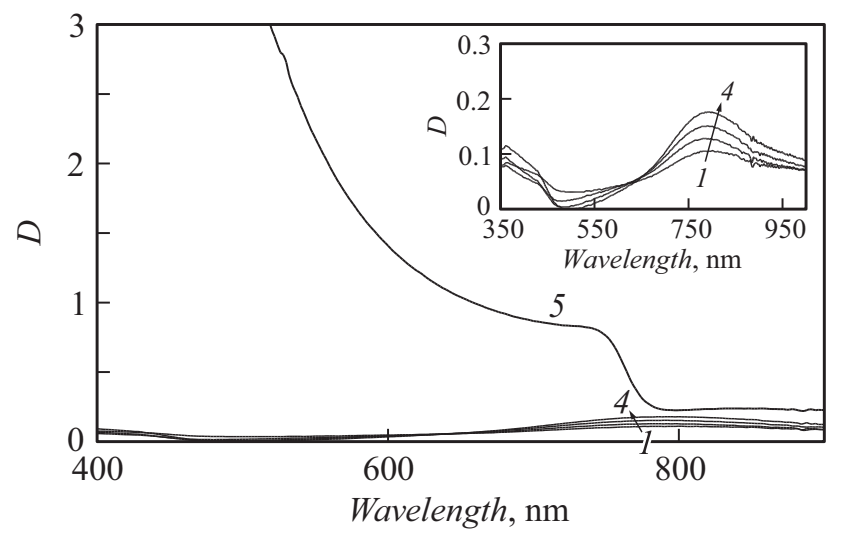

Рис. 1. Спектры поглощения слоя комплекса ПАНИ-ПАМПСК, полученного методом струйной печати для $N=2$ (1), 3 (2), 4 (3), 5 (4), и слоя перовскита, нанесенного на слой ПАНИ-ПАМПСК при $N=4(5)$. 

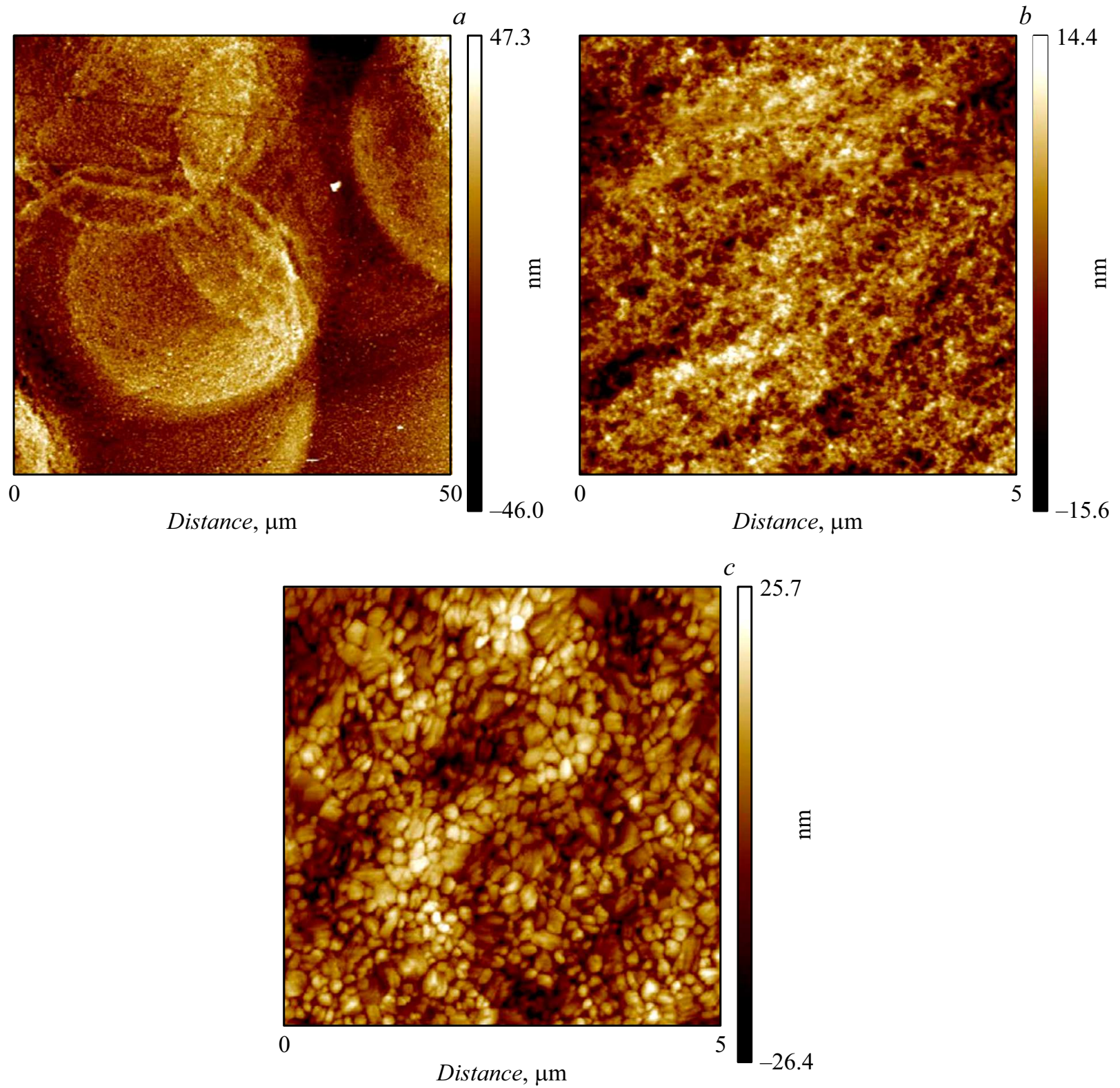

Рис. 2. АСМ-изображения слоя ПАНИ-ПАМПСК, полученного методом струйной печати при $N=4$, в масштабе 50 (a) и $5 \mu \mathrm{m}(b)$, а также слоя перовскита в масштабе $5 \mu \mathrm{m}(c)$.

фотоактивной композиции Р3НТ:РС71ВМ [15] было показано, что наиболее высокие характеристики имеют устройства со слоем ПАНИ-ПАМПСК с соотношением анилин:ПАМПСК, равным $1: 1.5 \mathrm{~mol} / \mathrm{g}$-equivalent сульфокислотных групп.

Целью настоящей работы является определение оптимального режима нанесения методом струйной печати ДТС из водного раствора комплекса ПАНИ-ПАМПСК при создании перовскитного СЭ.

ПАНИ синтезировался методом окислительной полимеризации анилина при комнатной температуре в присутствии ПАМПСК $\left(M W \sim 2 \cdot 10^{6}\right.$, Sigma-Aldrich) $[13,15]$. Разработанный для печати водный раствор комплекса ПАНИ-ПАМПСК имел концентрацию
$3.4 \mathrm{mg} / \mathrm{ml}$ и динамическую вязкость $1.8 \mathrm{cP}$. Вязкость раствора определялась на вискозиметре Уббелоде при температуре $30^{\circ} \mathrm{C}$ [15]. Печать ПАНИ-ПАМПСК на стеклянную подложку с оптически прозрачным электропроводящим слоем ITO (ITO - indium tin oxide), подогретую до $28-30^{\circ} \mathrm{C}$, производилась с помощью типового струйного принтера Epson Stylus Photo P50 [15]. Число печатных слоев $N$ в ДТС меняли от 2 до 5 .

Напечатанные слои переносили в атмосферу аргона и отжигали в течение $10 \mathrm{~min}$ при $70^{\circ} \mathrm{C}$ для удаления остатков воды. На слой ПАНИ-ПАМПСК наносился слой перовскита $\mathrm{CH}_{3} \mathrm{NH}_{3} \mathrm{PbI}_{3}$ толщиной $400 \mathrm{~nm}$ согласно методу, описанному ранее в $[16,17]$. Далее методом термического напыления в вакууме 
Характеристики СЭ с ДТС на основе комплекса ПАНИ-ПАМПСК, полученного методом струйной печати

\begin{tabular}{c|c|c|c|c|c}
\hline$N$ & $\Delta h, \mathrm{~nm}$ & $J_{s c}, \mathrm{~mA} / \mathrm{cm}^{2}$ & $V_{o c}, \mathrm{~V}$ & $F F$ & PCE, \% \\
\hline 2 & $50 \pm 5$ & 17.08 & 0.85 & 0.64 & 9.25 \\
3 & $40 \pm 5$ & 17.03 & 0.94 & 0.61 & 9.78 \\
4 & $30 \pm 5$ & 18.37 & 0.94 & 0.61 & 10.57 \\
5 & $20 \pm 5$ & 17.72 & 0.91 & 0.63 & 10.20
\end{tabular}

Примечание. $\Delta h-$ перепад профиля поверхности слоя ПАНИ-ПАМПСК, $J_{s c}$ - ток короткого замыкания, $V_{o c}-$ напряжение открытой цепи, $F F-$ фактор заполнения, РСЕ - КПД солнечного элемента.

наносились последовательно электронный транспортный слой фуллерена $\mathrm{C}_{60}$ (Ossila Ltd.), блокирующий слой 2, 9-диметил-4, 7-дифенил-1, 10-фенантролина (Sigma-Aldrich) и электрод Al толщиной 40, 7 и $80 \mathrm{~nm}$ соответственно.

Электронные спектры поглощения слоев ПАНИ-ПАМПСК и перовскита в УФ-видимой и ближней ИК-области спектра регистрировались на двулучевом спектрофотометре „Shimadzu UV-3101PC“. Атомная силовая микроскопия (АСМ) поверхности образцов проводилась на Enviroscope ACM-микроскопе с контроллером Nanoscope V (Bruker). Толщины слоев определялись с помощью стилусного профилометра KLA-Tencor D-100 Profiler. Измерения вольт-амперных характеристик образцов СЭ выполнялись с помощью источника-измерителя Keithley 2400 и имитатора солнечного излучения Oriel 96000 (Newport Corp.) при интенсивности $P_{i n}=100 \mathrm{~mW} / \mathrm{cm}^{2}$ (условие АМ 1.5) в герметичном боксе с сухой атмосферой аргона.

На рис. 1 показаны спектры поглощения слоев комплекса ПАНИ-ПАМПСК для разного числа $N$. Спектры имеют форму, характерную для проводящей формы ПАНИ (эмеральдина), с максимумом на длине волны в области $800 \mathrm{~nm}$ (рис. 1, вставка), связанным с поглощением локализованных поляронов [18]. С ростом числа слоев поглощение пленки ПАНИ-ПАМПСК повышается, но в целом этот вклад в поглощение слоя перовскита (рис. 1, кривая 5) пренебрежимо мал. При этом поглощение фотоактивного слоя перовскита охватывает всю видимую область спектра.

На рис. 2 представлены АСМ-изображения поверхности напечатанного слоя ПАНИ-ПАМПСК при $N=4$. Слой сильно неравномерен по толщине. На изображении его поверхности (рис. 2,a) видны высохшие капли со средним диаметром $30 \mu \mathrm{m}$, а глубина от впадины до края капли составляет 40-60 nm. Внутри капли (рис. 2,b) ПАНИ-ПАМПСК имеет характерную глобулярную структуру, как и у слоя, нанесенного путем полива из раствора (drop casting) [14].

Измерения поверхности слоев ПАНИ в микромасштабе с помощью профилометра показали (см. таблицу), что перепад профиля поверхности максимален в случае $N=2$. При этом в слое имеются области с толщи- ной менее $10 \mathrm{~nm}$ (вплоть до полного его отсутствия). С увеличением $N$ перепады профиля поверхности слоев уменьшаются благодаря более равномерному распределению и перекрыванию соседних капель.

На рис. 2, с представлены АСМ-изображения слоя перовскита, нанесенного поверх слоя ПАНИ-ПАМПСК. Видно, что средний поперечный размер кристаллов составляет 200-300 nm, а максимальный достигает $500 \mathrm{~nm}$. Как известно [1], такие размеры микрокристаллов обеспечивают наибольшую эффективность перовскитного СЭ. Важно отметить, что морфология поверхности слоя и размеры кристаллов перовскита не зависят от числа $N$ при печати слоя ПАНИ.

В таблице представлены фотовольтаические характеристики перовскитных СЭ с ДТС на основе комплекса ПАНИ-ПАМПСК. Для каждого $N$ приведены усредненные значения характеристик, измеренные на десяти СЭ. Разброс значений составляет не более $2 \%$ относительно средней величины. Анализируя данные таблицы, можно видеть, что с увеличением числа $N$ перепады профиля поверхности слоя уменьшаются, а КПД устройств растет. При этом максимальные значения КПД и тока короткого замыкания наблюдаются для СЭ с ДТС, напечатанным при условии $N=4$, а в случае ДТС, полученного при $N=5$, характеристики СЭ снижаются. Мы полагаем, что в образцах с ДТС, напечатанными при $N=2$ и 3 , на участках поверхности ITO непокрытых ДТС эффективность переноса дырок из перовскита и, как следствие, КПД понижены. С другой стороны, снижение перепада профиля ДТС при $N=5$ делает эффективную площадь границы раздела ДТС и слоя перовскита меньше, чем в случае образцов ДТС с $N=4$.

Таким образом, показана возможность использования метода струйной печати для нанесения ДТС на основе водного раствора комплекса ПАНИ-ПАМПСК для перовскитного СЭ. Установлено оптимальное число печатных слоев ПАНИ-ПАМПСК в ДТС $(N=4)$, которое обеспечивает наибольшую эффективность $\mathrm{C} Э$.

\section{Благодарности}

Атомная силовая микроскопия и спектральные измерения выполнены на оборудовании ЦКП ФМИ ИФХЭ PAH.

\section{Финансирование работы}

Исследование выполнено при финансовой поддержке Российского научного фонда (проект № 18-13-00409) и Министерства науки и высшего образования РФ (оборудование).

\section{Конфликт интересов}

Авторы заявляют, что у них нет конфликта интересов. 


\section{Список литературы}

[1] Jung H.S., Park N.-G. // Small. 2015. V. 11. P. 10-25.

[2] Jeon N.J., Na H., Jung E.H., Yang T.Y., Lee Y.G., Kim G., Shin H.W., Seok S.I., Lee J., Seo J. // Nature Energy. 2018. V. 3. P. $682-689$.

[3] Wang S., Sakurai T., Wen W., Qi Y. // Adv. Mater. Interfaces. 2018. V. 5. P. 1800260.

[4] Singh A., Katiyar M., Garg A. // RSC Adv. 2015. V. 5. P. 78677-78685.

[5] Lee K., Yu H., Lee J.W., Oh J., Bae S., Kim S.K., Jang J. // J. Mater. Chem. C. 2018. V. 6. P. 6250-6256.

[6] Lee K., Cho K.H., Ryu J., Yun J., Yu H., Lee J., Na W., Jang J. // Electrochim. Acta. 2017. V. 224. P. 600-607.

[7] Lim K.-G., Ahn S., Kim H., Choi M.-R., Huh D.H., Lee T.-W.// Adv. Mater. Interfaces. 2016. V. 3. P. 1500678.

[8] Xiao Y., Han G., Chang Y., Zhou H., Li M., Li Y. // J. Power Sources. 2014. V. 267. P. 1-8.

[9] Chiolerio A., Bocchini S., Porro S. // Adv. Funct. Mater. 2014. V. 24. P. 3375-3383.

[10] Kulkarni M.V., Apte S.K., Naik S.D., Ambekar J.D., Kale B.B. // Sensors Actuators B. 2013. V. 178. P. 140-143.

[11] Crowley K., Smyth M.R., Killard A.J., Morrin A. // Chem. Papers. 2013. V. 67. P. 771-780.

[12] Brannelly N.T., Killard A.J. // Talanta. 2017. V. 167. P. $296-$ 301.

[13] Якобсон О.Д., Грибкова О.Л., Некрасов А.А., Тверской В.А., Иванов В.Ф., Мельников П.В., Поленов Е.А., Ванников А.В. // Физикохимия поверхности и защита материалов. 2016. Т. 52. № 6. С. 613-620.

[14] Iakobson O.D., Gribkova O.L., Tameev A.R., Nekrasov A.A., Saranin D.S., Di Carlo A. // J. Ind. Eng. Chem. 2018. V. 65. P. 309-317.

[15] Грибкова О.Л., Сафьянова Л.В., Тамеев А.Р., Лыпенко Д.А., Тверской В.А., Некрасов А.А. // Письма в ЖТФ. 2018. T. 44. B. 6. C. 34-41.

[16] Saranin D.S., Mazov V.N., Luchnikov L.O., Lypenko D.A., Gostishev P.A., Muratov D.S., Podgorny D.A., Migunov D.M., Didenko S.I., Orlova M.N., Kuznetsov D.V., Tameev A.R., Di Carlo A. // J. Mater. Chem. C. 2018. V. 6. P. 6179-6186.

[17] Якобсон О.Д., Грибкова О.Л., Тамеев А.Р., Теруков Е.И. // Письма в ЖТФ. 2019. Т. 45. В. 16. С. 3-5.

[18] Nekrasov A.A., Ivanov V.F., Vannikov A.V. // J. Electroanal. Chem. 2000. V. 482. P. 11-17. 